First report of Eucoleus boehmi in red foxes (Vulpes vulpes) in Denmark, based on coprological examination

Al-Sabi, Mohammad M; Kapel, Christian Moliin Outzen

Published in:

Acta Parasitologica

DOI:

10.2478/s11686-013-0182-2

Publication date:

2013

Document version

Publisher's PDF, also known as Version of record

Citation for published version (APA):

Al-Sabi, M. M., \& Kapel, C. M. O. (2013). First report of Eucoleus boehmi in red foxes (Vulpes vulpes) in Denmark, based on coprological examination. Acta Parasitologica, 58(4), 570-576.

https://doi.org/10.2478/s11686-013-0182-2 


\title{
First report of Eucoleus boehmi in red foxes (Vulpis vulpis) in Denmark, based on coprological examination
}

\author{
Mohammad Nafi Solaiman Al-Sabi ${ }^{12 *}$ and Christian Moliin Outzen Kapel ${ }^{1}$ \\ ${ }^{1}$ Department of Plants and the Environment, Faculty of Sciences, University of Copenhagen, Thorvaldsensvej 40, \\ DK-1871 Frederiksberg C, Denmark; ${ }^{2}$ Section for Bacteriology, Pathology and Parasitology, Technical University of Denmark, \\ Bülowsvej 27, DK-1870 Frederiksberg C, Denmark
}

\begin{abstract}
Red foxes can be infected with diverse range of parasite species that can be transmitted to humans and pet animals, and the differential diagnosis is essential for veterinary and zoonotic risk assessment. In the present study, faecal flotation and microscopy of parasite eggs was done on 31 foxes originating from two distant localities in Denmark, the city of Copenhagen in the north east part of the island Zealand and from the southern part of the peninsular Jutland. In total, eggs of Eucoleus boehmi were recovered from a surprisingly high number of foxes ( $\mathrm{n}=22$ samples; $71 \%)$. The findings represent the first observations of $E$. boehmi in Denmark, which is likely an overlooked infection of the upper respiratory tract of red foxes, which can be also found in other canids. Several morphological features of the eggs of E. boehmi can be used to distinguish it from other the closely related trichuroid eggs. Detecting cardiopulmonary parasites by faecal examination can be indicative of the presence of cardiopulmonary parasites based on the more sensitive post mortem analysis.
\end{abstract}

\section{Keywords}

Eucoleus boehmi, Eucoleus aerophilus, Angiostrongylus vasorum, Crenosoma vulpis, egg morphology, diagnosis

\section{Introduction}

Eucoleus (Capillaria) boehmi is commonly known as the nasal worm of dogs and foxes and was first recovered from a red fox in Germany (Supperer 1953). The life cycle of E. boehmi is not described yet and attempts to transmit $E$. boehmi to helminthnaive dogs by ingestion of $E$. boehmi eggs, ingestion of earthworms fed on eggs and intra-nasal inoculation of eggs were unsuccessful (Muchmore 1998). A cohort study for six and eight years on naturally infected dogs with $E$. boehmi revealed that the faecal output persisted despite a clean, isolated environment (Muchmore 1998). Infection with E. boehmi can cause mild respiratory signs such as sneezing and nasal discharge (Campbell and Little 1991), however, up to 88 worms were isolated from a naturally infected dog that did not exhibit any clinical signs (Muchmore 1998). The present paper describes the recovery of eggs of E. boehmi from red foxes in Denmark for the first time.

\section{Materials and Methods}

In the period from 2006 to 2008, 23 road-killed foxes were collected from Copenhagen greater area in the island Zealand, and eight hunted foxes from the southern region of the peninsular Jutland, that is geographically connected to mainland Europe. Foxes sampled were initially frozen at $-80^{\circ} \mathrm{C}$ for at least 4 days for safety reasons. Trachea, heart and bronchi were opened with scissors and bronchioles and the rest of the lung tissue were dissected using a metallic needle to free nematodes. The dissected organs were washed with luke tap water $\left(30-35^{\circ} \mathrm{C}\right)$ into a $212 \mu \mathrm{m}$ sieve by means of a water jet, and collected worms were identified under a stereo microscope (x10) (Soulsby 1982). Unfortunately, nasal passages and frontal sinuses were not examined due to lacking of logistics related to skull examination (instruments and licence for sowing skulls). Faecal samples were collected from the colon of the animals sampled, and trichuroid eggs were isolated by flotation-sieving method modified after Davidson et al. (2009). Briefly two grams of faecal material were mixed with sugar-salt floatation fluid (specific gravity 1.2) and vortexed. The suspension was centrifuged at $1600 \mathrm{~g}$ for 10 minutes and the supernatant was poured through a $21 \mu \mathrm{m}$ mesh size nylon filter. The retained material in the sieve was washed with distilled water and the remaining sediment was poured into a $3.5 \mathrm{ml}$ petri-dish and examined using an inverted microscope at $40 \times$ magnification. Once detected, trichuroid eggs were aspirated by glass pipettes 
and transferred to a glass slide and mounted with a cover slip and thereafter examined under light and phase contrast microscope (Olympus AX-70) at $200 \times-400 \times$ magnifications. Differential diagnosis of trichuroid eggs was based on egg size, shape and color, plug shape, embryo and the surface structure of the outer egg-shell (Butterworth and Beverley-Button 1980; Campell 1991; Campell and Little 1991; Schoning et al. 1993).

\section{Results and Discussion}

By post mortem examination, three parasite species were detected: Angiostrongylus vasorum; Eucoleus aerophilus; and Crenosoma vulpis (Table I). Only one fox was free from cardiopulmonary parasites, 13 were infected with one species, 14 were infected with two species and three were infected with

Table I. Cardiopulmonary parasites detected in 31 foxes based on post mortem and faecal examination

\begin{tabular}{|c|c|c|c|c|c|c|c|c|}
\hline \multirow[b]{2}{*}{ 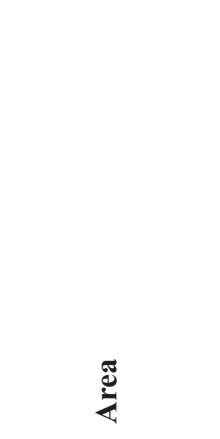 } & \multirow[b]{2}{*}{ 要 } & \multicolumn{3}{|c|}{ Results of post mortem examination } & \multicolumn{4}{|c|}{ Results of faecal examination } \\
\hline & & 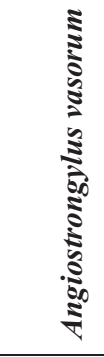 & 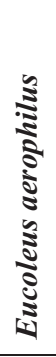 & 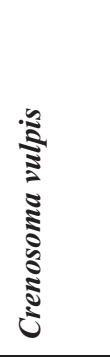 & 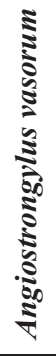 & 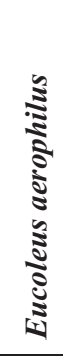 & 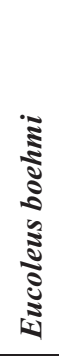 & 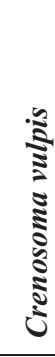 \\
\hline Jutland & 1 & & $\mathrm{X}$ & & & $\mathrm{X}$ & $\mathrm{X}$ & \\
\hline Jutland & 4 & & X & $X$ & & & X & X \\
\hline Jutland & 7 & & X & & & X & X & \\
\hline Jutland & 9 & & X & & & & X & \\
\hline Jutland & 11 & & $\mathrm{X}$ & & & & & \\
\hline Jutland & 18 & & $\mathrm{X}$ & & & & X & \\
\hline Jutland & 48 & & $\mathrm{X}$ & & & X & $\mathrm{X}$ & \\
\hline Jutland & 49 & & X & X & & & X & \\
\hline Zealand & 6 & $\mathrm{X}$ & $\mathrm{X}$ & $\mathrm{X}$ & $\mathrm{X}$ & $\mathrm{X}$ & $\mathrm{X}$ & \\
\hline Zealand & 17 & $\mathrm{X}$ & $\mathrm{X}$ & & $\mathrm{X}$ & & & \\
\hline Zealand & 25 & $\mathrm{X}$ & $\mathrm{X}$ & X & $\mathrm{X}$ & X & X & \\
\hline Zealand & 78 & $\mathrm{X}$ & $\mathrm{X}$ & & $\mathrm{X}$ & & $\mathrm{X}$ & \\
\hline Zealand & 79 & $\mathrm{X}$ & $\mathrm{X}$ & & & X & $\mathrm{X}$ & \\
\hline Zealand & 81 & $\mathrm{X}$ & $\mathrm{X}$ & & & & & \\
\hline Zealand & 82 & $\mathrm{X}$ & $\mathrm{X}$ & $\mathrm{X}$ & & $\mathrm{X}$ & & $\mathrm{X}$ \\
\hline Zealand & 83 & & & & & & $\mathrm{X}$ & \\
\hline Zealand & 85 & $\mathrm{X}$ & $\mathrm{X}$ & & & $\mathrm{X}$ & $\mathrm{X}$ & \\
\hline Zealand & 86 & & $\mathrm{X}$ & & & $\mathrm{X}$ & $\mathrm{X}$ & \\
\hline Zealand & 92 & X & & & X & & $\mathrm{X}$ & \\
\hline Zealand & 93 & $\mathrm{X}$ & & & $\mathrm{X}$ & & $\mathrm{X}$ & \\
\hline Zealand & 94 & $\mathrm{X}$ & & & $\mathrm{X}$ & & $\mathrm{X}$ & \\
\hline Zealand & 96 & & $\mathrm{X}$ & & & $\mathrm{X}$ & & \\
\hline Zealand & 97 & $\mathrm{X}$ & & & $\mathrm{X}$ & & $\mathrm{X}$ & \\
\hline Zealand & 98 & $\mathrm{X}$ & X & & & & & \\
\hline Zealand & 99 & $\mathrm{X}$ & $\mathrm{X}$ & & & $\mathrm{X}$ & & \\
\hline Zealand & 101 & $\mathrm{X}$ & $\mathrm{X}$ & & X & $\mathrm{X}$ & X & \\
\hline Zealand & 102 & $X$ & $X$ & & & & & \\
\hline Zealand & 103 & $\mathrm{X}$ & $\mathrm{X}$ & & X & $\mathrm{X}$ & X & \\
\hline Zealand & 104 & & $\mathrm{X}$ & $\mathrm{X}$ & & $\mathrm{X}$ & & X \\
\hline Zealand & 105 & & $\mathrm{X}$ & & & $\mathrm{X}$ & $\mathrm{X}$ & \\
\hline Zealand & 107 & $\mathrm{X}$ & $\mathrm{X}$ & & $\mathrm{X}$ & $\mathrm{X}$ & $\mathrm{X}$ & \\
\hline Total & 31 & 18 & 26 & 6 & 11 & 16 & 22 & 3 \\
\hline Prevalence (\%) & 100 & 58 & 84 & 19 & 35 & 52 & 71 & 10 \\
\hline
\end{tabular}



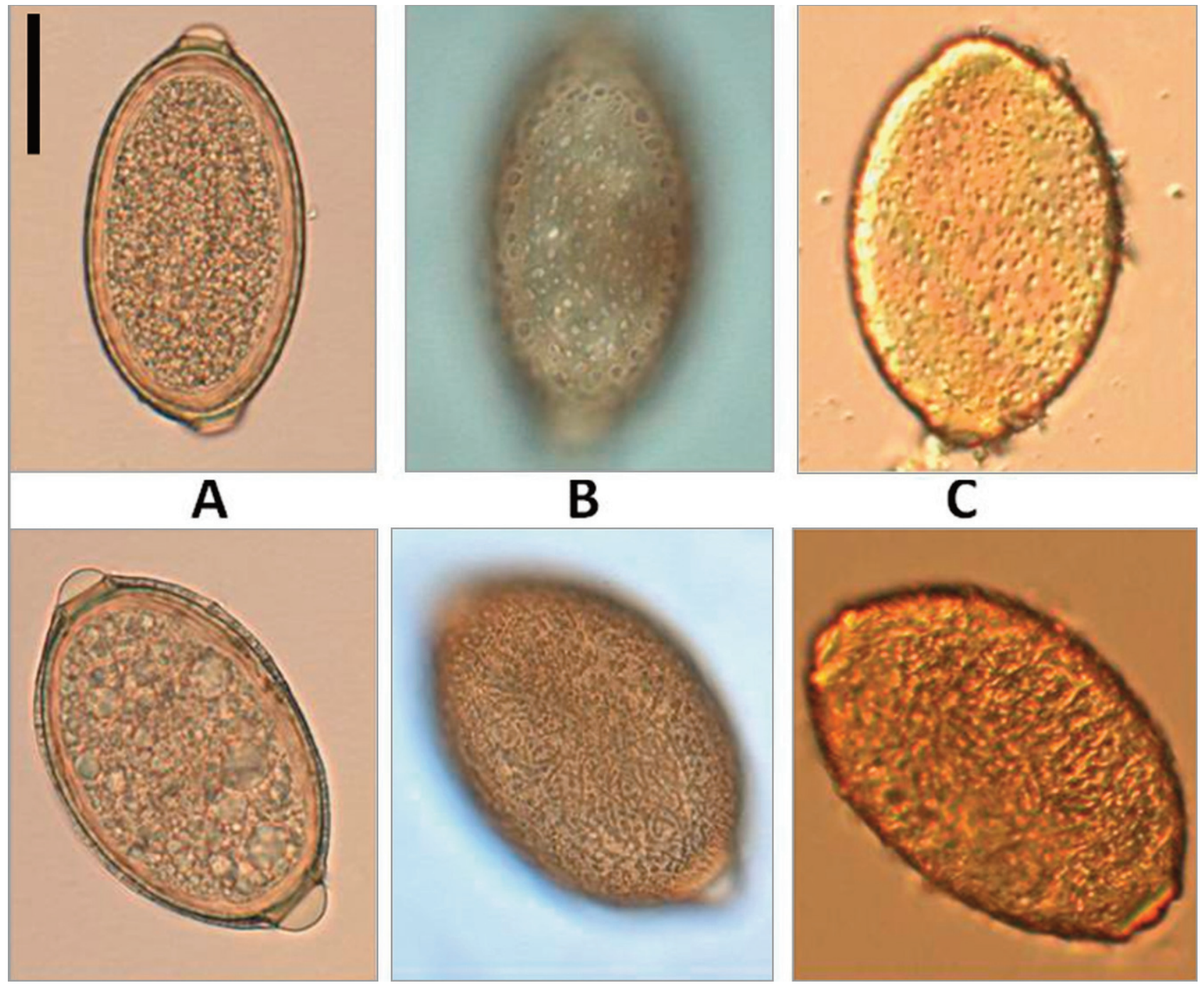

Fig. 1. Egg shell morphology of Eucoleus boehmi and Eucoleus aerophilus. Outer shell morphology of eggs of Eucoleus boehmi (upper row) compared to Eucoleus aerophilus (lower row) as seen using direct light microscopy (A), by fine adjustment focusing on the outer shell plane (B) or by using a phase contrast microscopy (C). Eggs were scaled to fit the presented scale bar on the upper left side of the figure (=20 $\mu \mathrm{m})$

three species. Based on faecal examination, 22 samples contained eggs of E. boehmi (71\%; Fig. 1), five of which belonged to foxes that did not have E. aerophilus at post mortem examination. Eggs of E. boehmi were 55.4-67.5 $\mu \mathrm{m} \times 30.3-$ $35 \mu \mathrm{m}$, whereas eggs of eggs of E. aerophilus were $60.7-$ $64.3 \mu \mathrm{m} \times 28.5-30.4 \mu \mathrm{m}$. All foxes examined in this study were infected with at least one Eucoleus spp.

We noticed a marked difference in the prevalence of cardiopulmonary parasites based on faecal examination compared to that based on post mortem examination. Nonetheless, the recovery of lungworm larvae and/or eggs by faecal examination underestimated the post mortem recovery of E. aerophilus worms by $32 \%, A$. vasorum by $23 \%$ and $C$. vulpis by $9 \%$ (Fig. 2). Over-representation of parasite eggs in faeces as a result of coprophagia could not be determined in the current study, but is not likely to affect the current results since none of the foxes that were free from a certain helminth species had parasite eggs or larvae of that species in its faeces, and also due to the underestimation of cardiopulmonary infections based on faecal examination. This underestimated detection of $A$. vasorum and C. vulpis might be caused by prepatent infections or the intermittent and irregular pattern of larval excretion (Willesen et al. 2004), or the possible damage of larvae when isolated by floatation medium (Traversa et al. 2010). Reduced recovery of nematode eggs could be a result of damaged eggs because of freezing and thawing or the use of improper floatation medium or techniques (Dryden et al. 2005).

The gold standard method for the recovery of viable lungworm larvae is the Baermann technique (Willesen et al. 2004). In this study, fox carcasses were already frozen and therefore implementing the Baermann technique was not valid. Instead, faecal flotation was found to be effective in isolating first stage larvae of A. vasorum (Al-Sabi et al. 2010; Schnyder et al. 


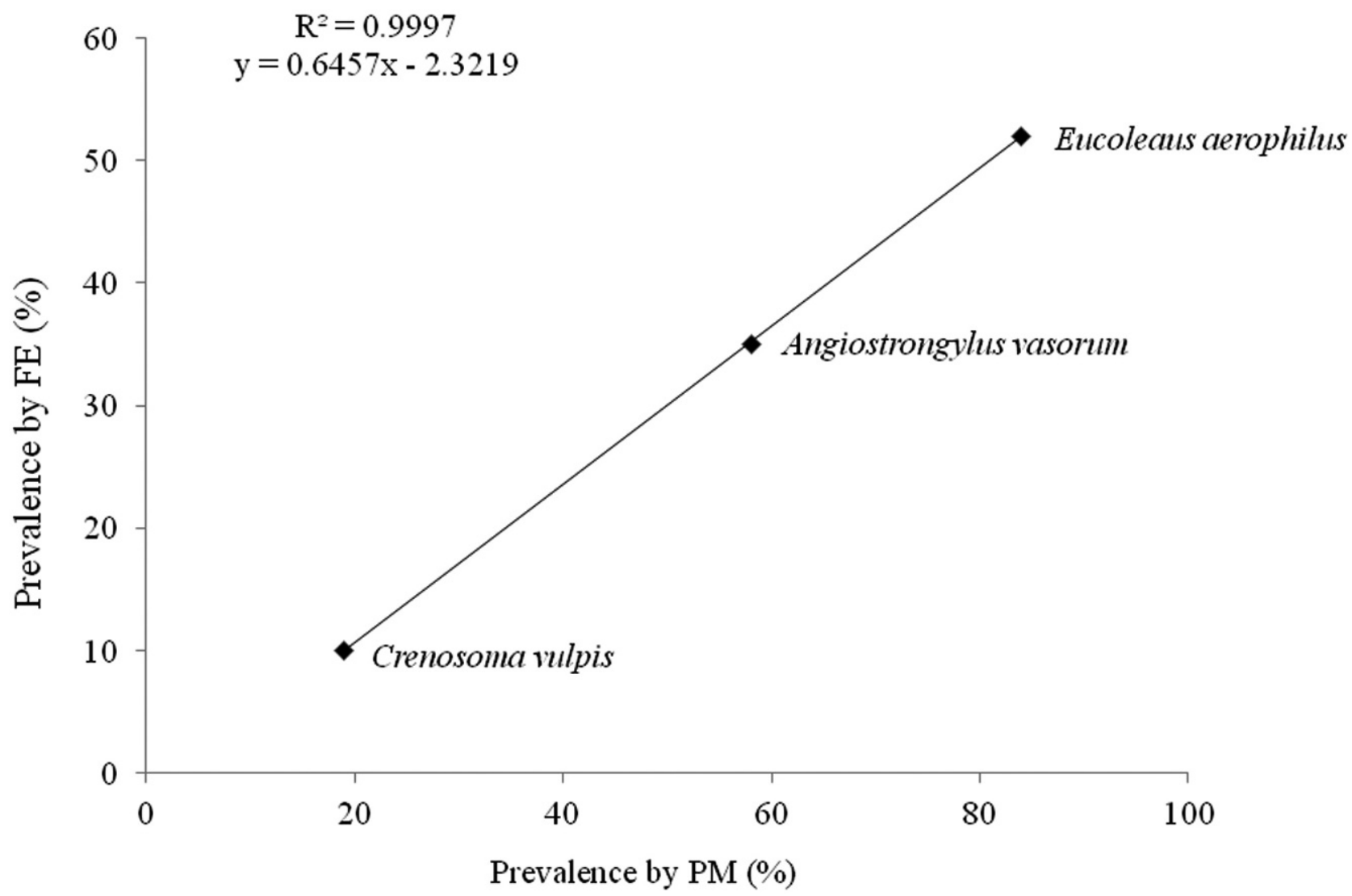

Fig. 2. Correlation between the prevalence of cardiopulmonary parasites based on post mortem and faecal examination methods. Correlation coefficient $\left(\mathrm{R}^{2}\right)$ presented on the figure indicates strong positive correlation between the reported prevalence of cardiopulmonary parasites of 31 foxes based on post mortem analysis (PM) and that reported by faecal egg isolation (FE) method. Correlation equation can be used to predict the prevalence based on faecal examination

2011), although it is not the preferred technique (Conboy 2009). Despite that, the strong linear association $\left(\mathrm{R}^{2}=1\right)$ between the two methods suggest that faecal examination can be used for estimating the presence of cardiopulmonary parasites in foxes based on environmental sampling of faeces, and thereby reducing the costs and logistic requirements for performing post mortem analysis of carcasses. However, we could not predict the presence of $E$. boehmi worms in foxes in Denmark due to lacking comparative data on recovery of worms by post mortem examination.

The reported size range of trichuroid eggs in the literature was markedly overlapping (Fig. 3), therefore other morphological features should be used to differentiate between these eggs. Eggs of Trichuris vulpis are characterized by its relative larger size, brownish to yellowish color, its polar plugs are symmetrically positioned in relation to the axis of the egg, the surface of its eggs is smooth and the presence of characteristic rings on the basis of the plugs (Campbell 1991; Campell and Little 1991; Schoning et al. 1993; Conboy 2009; Traversa et al. 2011; Di Cesare et al. 2012). In this study, the colon and the urinary bladder of the foxes sampled were not examined and eggs of T. vulpis and Personema plica were not detected. Based on the reported low prevalence of $T$. vulpis in foxes in
Denmark; $0.5 \%$ of 1040 foxes (Saeed et al. 2006), and because the sample examined in this study was limited, the probability of detecting T. vulpis was extremely low. On the other hand, P. plica is very abundant in foxes in Denmark; $81 \%$ of 1040 foxes (Saeed et al. 2006). Despite that P. plica is a bladder nematode, its eggs can be accidently ingested during grooming and therefore could be, infrequently, found in faeces of infected animals (Campbell 1991). However, faecal examination is not the typical methodology for detecting infections with P. plica, but if present, the eggs can be clearly distinguished morphologically from other trichuroid eggs (Campbell 1991).

The ability to differentiate between E. boehmi and E. aerophilus is important because they differ in terms of pathogenicity and zoonotic potential (Traversa et al. 2010; Di Cesare et al. 2012). Furthermore, mixed infections with these two species naturally occur (Di Cesare et al. 2012); based on faecal analysis in this study, 12 out of 31 foxes $(39 \%)$ had mixed infections with E. boehmi and E. aerophilus, and another study based on post mortem examination reported mixed infections in $94 \%$ of 88 foxes (Davidson et al. 2006). The bipolar plugs in eggs of $E$. boehmi were previously said to be blister-like and more protruding outwards than those of E. aerophilus (Campbell 1991; Campell and Little 1991; Con- 


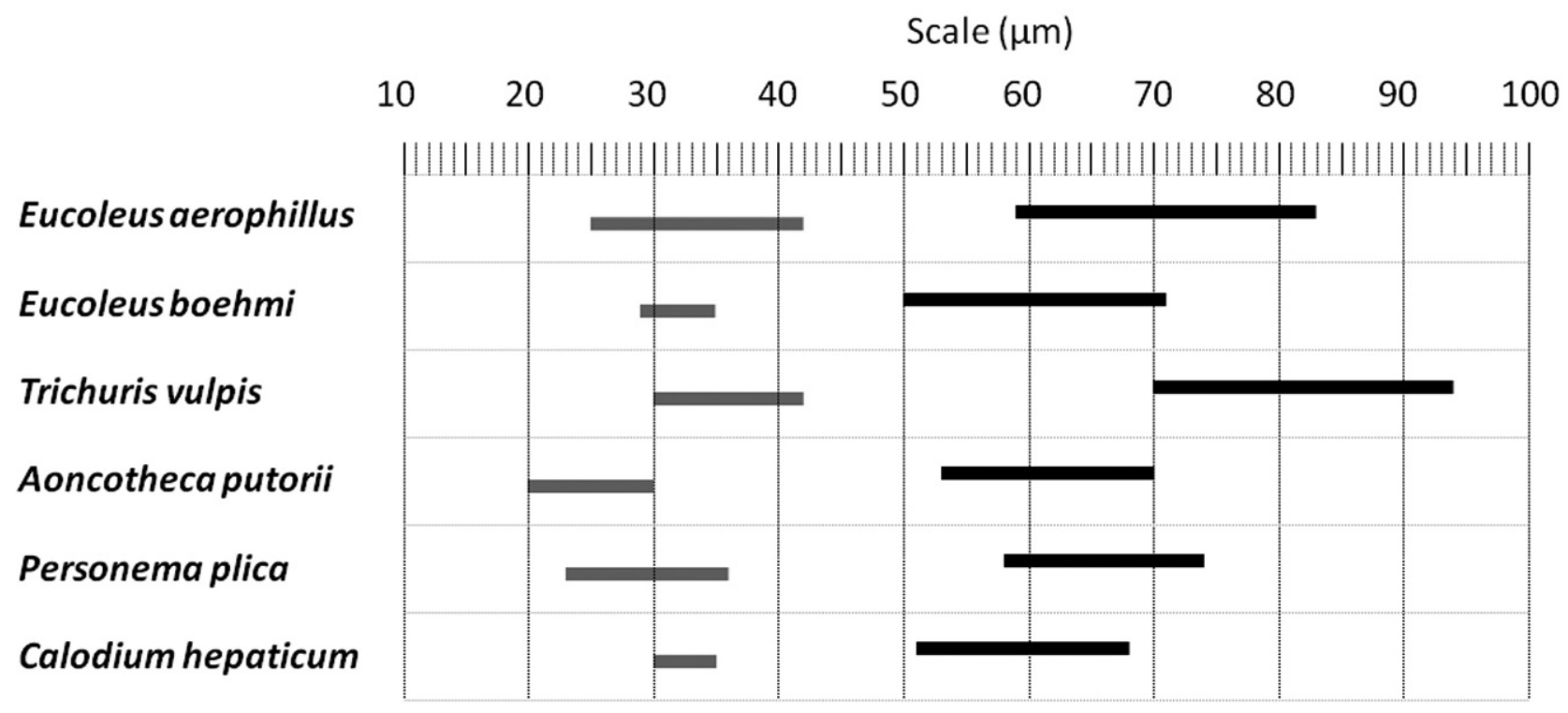

Fig. 3. Reported size ranges of trichuroid eggs in the literature (Supperer 1953; Butterworth and Beverley-Burton 1980; Campbell 1991; Campell and Little 1991; Schoning et al. 1993; Moravec 2000; Romashov et al. 2000; Conboy 2009; Traversa et al. 2010; Di Cesare et al. 2012). Size range of length (black) and width (grey) of trichuroid eggs commonly recovered in many carnivore species.

boy 2009), but we did not see this feature constantly and it was hard to evaluate (Fig. 1). The embryo is said to be more differentiated in $E$. boehmi leaving more space inside the egg compared to eggs of E. aerophilus (Campell and Little 1991). However, Muchmore (1998) reported that $90 \%$ of E. boehmi eggs freshly isolated from faeces had multicellular embryo with space between it and the egg shell, and $6 \%$ of the eggs had undifferentiated zygotes that completely filled the interior space of the eggs, while the rest were eggs that had vermiform to fully developed larvae. The most important characteristic of E. boehmi eggs is the pitted appearance of the shell that is given by the presence of several pits that are irregularly scattered (Fig. 1). The pits on E. boehmi eggs are of different sizes and are generally round to oval, which is different from the netted appearance of eggs of E. aerophilus (Supperer 1953; Butterworth and Beverley-Burton 1980; Campbell 1991; Campell and Little 1991; Schoning et al. 1993; Romashov et al. 2000; Conboy 2009; Traversa et al. 2010; Magi et al. 2012).

Detection of E. boehmi in this study was done by thorough microscopic examination of the eggs which allowed for separation of $E$. boehmi from other trichuroid species. Only a few studies considered the morphological difference when faecal eggs were examined (Campbell and Little 1991; Traversa et al. 2009). Hence, the presence of Capillarid eggs was often referred to as Eucoleus (Capillaria) spp., while other studies stated that E. boehmi might have been confused with other trichuroid eggs (Campbell and Little 1991; Lassing et al. 1998; Sreter et al. 2003; Conboy 2009; Traversa et al. 2010). A few studies based on post mortem analysis of cardiopulmonary organs in foxes included steps of examining the nasal and cranial sinuses (Table II), leaving a gap in our knowledge on $E$. boehmi prevalence that might be under estimated (Campbell and Little 1991; Manas et al. 2005). Periodical egg

Table II. Reported prevalence of fox cardiopulmonary parasites in Europe by post mortem or faecal examination $(*)$

\begin{tabular}{|c|c|c|c|c|c|c|c|}
\hline Reference & Country & $\begin{array}{l}\text { Sample } \\
\text { size }\end{array}$ & $\begin{array}{c}\text { Nasal and } \\
\text { frontal sinuses } \\
\text { examined }\end{array}$ & $\begin{array}{c}\text { Eucoleus } \\
\text { boehmi }\end{array}$ & $\begin{array}{c}\text { Eucoleus } \\
\text { aerophilus }\end{array}$ & $\begin{array}{l}\text { Crenosoma } \\
\text { vulpis }\end{array}$ & $\begin{array}{l}\text { Angiostrongy- } \\
\text { lus vasorum }\end{array}$ \\
\hline Saeed et al. 2006 & Denmark & 1040 & No & Not reported & 74.1 & 17 & 48.6 \\
\hline Rajkovic-Janje et al. 2002 & Croatia & 85 & No & Not reported & 4.7 & 28.2 & 1 \\
\hline Gortazar et al. 1998 & Spain & 81 & No & Not reported & 34.8 & 3 & 20.7 \\
\hline Magi et al. 2009 & Italy & 129 & No & Not reported & 7 & 14.7 & 7 \\
\hline Sreter et al. 2003 & Hungary & 100 & Yes & 8 & 66 & 24 & 5 \\
\hline Davidson et al. 2006 & Norway & 181 & Yes & $51(\mathrm{n}=174)$ & $88(\mathrm{n}=181)$ & $58(\mathrm{n}=181)$ & 0 \\
\hline
\end{tabular}


excretion of E. boehmi, peaking every five to seven weeks (Schoning et al. 1993), also complicates its detection by faecal examination. Therefore, faecal samples collected on consecutive days from alive animals should be examined; otherwise collecting worms and eggs of E. boehmi could be done by applying nasal washing (Schoning et al. 1993), but not nasal swabs only (Magi et al. 2012). A study on 51 foxes in Canada recovered eggs of E. aerophilus in $68.6 \%$ of the examined faeces, whereas worms were recovered by post mortem in only $49 \%$ of the foxes (Nevarez et al. 2005). It was therefore concluded that prevalence of E. aerophilus could have been overestimated since only histological examination of lungs was practiced without examining nasal and frontal sinuses.

This is the first report of E. boehmi in foxes from geographically distant locations in Denmark, suggesting that the parasite may be relatively prevalent and widespread. Infections with E. boehmi could be found in companion dogs but with low prevalence (Conboy 2009; Traversa et al. 2010; Di Cesari et al. 2012; Magi et al. 2012). The implications of the present high prevalence of $E$. boehmi in foxes could not be assessed in this study, however transmission of $A$. vasorum between foxes and dogs in endemic areas was demonstrated by molecular analysis (Jefferies et al. 2010). Another factor that could perpetuate E. boehmi in nature is its probable transmission between wider range of wild and domesticated carnivore species. Together with the given limitation of recovering eggs of E. boehmi from faeces, the presence of this parasite in companion carnivores might be more frequent than expected (Conboy 2009).

\section{Conclusions}

Infections with Eucoleus boehmi are prevalent in foxes in Denmark and could be more abundant among other carnivores, but overlooked by microscopy due to the overlapping morphological similarities between trichuroid eggs. Faecal examination of wild and domesticated carnivores should include steps of examining the egg-shell for differentiating trichuroid infections.

Acknowledgements. Employees at the Department of Plants and the Environment are thanked for their help in the field and in the laboratories. This work was supported by a $\mathrm{PhD}$ grant from the Faculty of Sciences, University of Copenhagen, Denmark.

\section{References}

Al-Sabi M.N.S., Deplazes P., Webster P., Willesen J.L., Davidson R.K., Kapel C.M.O. 2010. PCR detection of Angiostrongylus vasorum in faecal samples of dogs and foxes. Parasitology Research, 107, 135-140. DOI: 10.1007/s00436-010-1847-5.

Borgsteede F.H. 1984. Helminth parasites of wild foxes (Vulpes vulpes L.) in The Netherlands. Zeitschrift für Parasitenkunde, 70, 281-285. DOI: 10.1007/BF00927813.
Butterworth E.W., Beverley-Burton M. 1980. The taxonomy of Capillaria spp. (Nematoda: Trichuroidea) in carnivorous mammals from Ontario, Canada. Systematic Parasitology, 1, 211-236.

Campbell B.G. 1991. Trichuris and other Trichinelloid nematodes of dogs and cats in the United States. Compendium on Continuing Education for the Practising Veterinarian - North American Edition, 13, 769-778.

Campbell B.G., Little M.D. 1991. Identification of the eggs of a nematode (Eucoleus boehmi) from the nasal mucosa of North American dogs. Journal of the American Veterinary Medical Association, 1, 1520-1523.

Conboy G.A. 2009. Helminth parasites of the canine and feline respiratory tract. Veterinary Clinics of North America: Small Animal Practice, 39, 1109-1126. DOI: 10.1016/j.cvsm.2009. 06.006 .

Davidson R.K., Gjerde B., Vikøren T., Lillehaug A., Handeland K.M. 2006. Prevalence of Trichinella larvae and extra-intestinal nematodes in Norwegian red foxes (Vulpes vulpes). Veterinary Parasitology, 136, 307-316. DOI: 10.1016/j.vetpar.2005. 11.015.

Davidson R.K., Oines O., Madslien K., Mathis A. 2009. Echinococcus multilocularis adaptation of a worm egg isolation procedure coupled with a multiplex PCR assay to carry out large-scale screening of red foxes (Vulpes vulpes) in Norway. Parasitology Research, 104, 509-514. DOI: 10.1007/s00436008-1222-y.

Di Cesare A., Castagnal G., Meloni1 S., Otranto D., Traversa D. 2012. Mixed trichuroid infestation in a dog from Italy. Parasite and Vectors, 25, 5:128. DOI: 10.1186/1756-3305-5128.

Dryden M.W., Payne P.A., Ridley R., Smith V. 2005. Comparison of common fecal flotation techniques for the recovery of parasite eggs and oocystis. Veterinary Therapeutics, 6, 15-28.

Eira C., Viganda J., Torres J., Miquel J. 2006. The helminth community of the red fox, Vulpes vulpes, in Dunas de Mira (Portugal) and its effect on host condition. Wildlife Biology in Practice, 2, 26-36. DOI: 10.2461/wbp.2006.2.5.

Gortazar C., Villafuerte R., Lucientes J., FernBndez-de-Luco D. 1998. Habitat related differences in helminth parasites of red foxes in the Ebro Valley. Veterinary Parasitology, 80, 75-81. DOI: 10.1016/S0304-4017(98)00192-7.

Jefferies R., Shaw S.E., Willesen J.L., Viney M.E., Morgan E.R. 2010. Elucidating the spread of the emerging canid nematode Angiostrongylus vasorum between Palaearctic and Nearctic ecozones. Infection, Genetics and Evolution, 10, 561-568. DOI: 10.1016/j.meegid.2010.01.013.

Lassing H., Prosl H., Hinterdorfer F. 1998. Parasites of the red fox (Vulpes vulpes) in Styria. (in German). Wiener Tierärztlichen Monatsschrift, 85, 116-122.

Magi M., Macchioni F., Dell'Omodarme M., Prati M.C., Calderini P., Gabrielli S., Iori A., Cancrini G. 2009. Endoparasites of red foxes (Vulpis vulpis) in Central Italy. Journal of Wildlife Diseases, 45, 881-885.

Magi M., Guardone L., Prati M.C., Torracca, B., Macchioni F. 2012. First report of Eucoleus boehmi (syn. Capillaria boehmi) in dogs in the north-western Italy, with scanning electron microscope of the eggs. Parasite, 19, 433-435.

Manas S., Ferrer D., Castellà J., López-Martín J.M. 2005. Cardiopulmonary helminth parasites of red foxes (Vulpes vulpes) in Catalonia, northeastern Spain. Veterinary Journal, 169, 118-120. DOI: 10.1016/j.tvj1.2003.12.011.

Moravec F. 2000. Review of capillariid and trichosomoidid nematodes from mammals in the Czech Republic and the Slovak Republic. Acta Societatis Zoologicae Bohemicae, 64, 271304. 
Muchmore C.E. 1998. A study of the nematode Capillaria boehmi (Supperer, 1953): A parasite in the nasal passages of the dog. PhD. Dissertation, Oklahoma State University, USA.

Nevarez A., Lopez A., Conboy G., Ireland W., Sims D. 2005. Distribution of Crenosoma vulpis and Eucoleus aerophilus in the lung of free-ranging red foxes (Vulpes vulpes). Journal of Veterinary Diagnostic Investigation, 17, 486-489.

Rajkovic-Janje R., Marinculic A., Bosnic S., Benic M., Vinkovic B., Mihaljevic Z. 2002. Prevalence and seasonal distribution of helminth parasites in red foxes (Vulpes vulpes) from the Zagreb County (Croatia). (in German). Zeitschrift für Jagdwissenschaft, 48, 151-160. DOI: 10.1007/BF02189989.

Romashov B.V. 2000. Three capillariid species (Nematoda, Capillariidae) from carnivores (Carnivora) and discussion of system and evolution of the nematode family Capillariidae. 1. Redescription of Eucoleus aerophilus and E. boehmi (In Russian). Zoologicheskiy Zhurnal, 79, 1379-1391.

Saeed I., Maddox-Hyttel C., Monrad J., Kapel C.M.O. 2006. Helminths of red foxes (Vulpes vulpes) in Denmark. Veterinary Parasitology, 139, 168-179. DOI: 10.1016/j.vetpar.2006. 02.015 .

Schnyder M., Maurelli M., Morgoglione M., Kohler L., Deplazes P., Torgerson P., Cringoli G., Rinaldi L. 2011. Comparison of faecal techniques including FLOTAC for copromicroscopic detection of first stage larvae of Angiostrongylus vasorum. Parasitology Research, 109, 63-69. DOI: 10.1007/s00436010-2221-3.

Schoning P., Dryden M.W., Gabbert N.H. 1993. Identification of a nasal nematode (Eucoleus boehmi) in greyhounds. Veterinary Research Communications, 17, 277-281. DOI: 10.1007/BF0 1839218.

Soulsby E.J.L. (Ed.). 1982. Helminths, Arthropods and Protozoa of domesticated animals. $7^{\text {th }}$ edition. Bailliére Tindall, London, UK, 266, 268 and 324 pp.

(Accepted: October 10, 2013)
Sreter T., Szell Z., Marucci G., Pozio E., Varga I. 2003. Extraintestinal nematode infections of red foxes (Vulpes vulpes) in Hungary. Veterinary Parasitology, 115, 329-334. DOI: 10.1016/ S0304-4017(03)00217-6.

Supperer R. 1953. Capillaria böhmi spec. nov., eine neue haarwurmart aus den stirnhöhlen des fuchses (in German). Zeitschrift für Parasitenkunde, 16, 51-55. DOI: 10.1007/BF00 260409.

Traversa D., Di Cesare A., Milillo P., Raffaella L., Otranto D. 2009. Infection by Eucoleus aerophilus in dogs and cats: Is another extra-intestinal parasitic nematode of pets emerging in Italy? Research in Veterinary Science, 87, 270-272. DOI: 10.1016/ j.rvsc.2009.02.006.

Traversa D., Di Cesare A., Conboy G. 2010. Canine and feline cardiopulmonary parasitic nematodes in Europe: emerging and underestimated. Parasites and Vectors, 23, 3:62. DOI: 10. 1186/1756-3305-3-62.

Traversa D., Di Cesare A., Lia R.P., Castagna G., Meloni S., Heine J., Strube K., Milillo P., Otranto D., Meckes O., Schaper R. 2011. New insights into morphological and biological features of Capillaria aerophila (Trichocephalida, Trichuridae). Parasitology Research, 109, S97-S104. DOI: 10.1007/s00436011-2406-4.

Willesen J.L., Moller J., Koch J., Lundorff-Jensen A., Kristensen AM. T. 2004. Early diagnosis of Angiostrongylus vasorum (French heartworm) and Crenosoma vulpis (The fox lungworm) is possible by means of modified Baermann test. Original text (in Danish): Tidlig diagnostik af Angiostrongylus vasorum (fransk hjerteorm) og Crenosoma vulpis (rævens lungeorm) hos hunde er mulig ved hjalp af modificeret Baermann test. Dansk Veterincertidsskrift, 87, 21-25. 